Netherlands Journal of

Geosciences

www.cambridge.org/njg

\section{Original Article}

Cite this article: de Pater CJ (Hans) and Shaoul JR. Stimulation for geothermal wells in the Netherlands. Netherlands Journal of Geosciences, Volume 98, e11. https://doi.org/ 10.1017/njg.2019.8

Received: 11 February 2019

Revised: 17 October 2019

Accepted: 30 October 2019

\section{Keywords:}

geothermal recovery; Netherlands; fracture stimulation

Author for correspondence:

Hans de Pater,

Email: hans.depater@fenixdelft.com

\title{
Stimulation for geothermal wells in the Netherlands
}

\section{C.J. (Hans) de Pater (1) and Josef R. Shaoul}

Fenix Consulting Delft BV, Poortweg 6A, 2612 PA Delft, the Netherlands

\section{Abstract}

Hydraulic fracturing is a long-established method of stimulating a well to improve the inflow or outflow potential. Hydraulic fracturing is the most successful stimulation method used by the oil and gas industry, and is also used for water injection and production wells around the world, even for drinking-water wells. Hydraulic fracturing creates a crack in the earth that is then filled with a highly conductive material (proppant). This fracture has a large inflow area compared to an unstimulated wellbore and provides a high-permeability path for the fluid to flow in or out of the reservoir.

Hydraulic fracturing has a long history of being used in hot dry rock (HDR) geothermal applications since the 1980s (Murphy \& Fehler, 1986). In those often very tight reservoirs, the aim is to create fracture networks that generate the reservoir flow capacity. In highpermeability formations, fracturing can potentially double the productivity of a well. In lowpermeability formations, well performance can be increased by a factor of 5-10 in most cases.

In this paper, we focus on two different scenarios of geothermal stimulation. The first is for permeable, porous formations where the heat exchange happens through the perfect contact between the fluid and the porous reservoir. Stimulation may then be necessary to create a small fracture if the pressure drop near the well is too large due to insufficient reservoir permeability. The other scenario is a formation at great depth, where the formation permeability is so extremely small that very long propped fractures would be needed to obtain sufficient flow or even where the porous system does not provide sufficient heat exchange but the heat exchange has to be facilitated by an artificial or stimulated fracture network: a so-called Enhanced Geothermal System.

For porous, permeable formations we will present examples of fracture treatments that can increase the flow rate so that the economics of the project is improved. In some formations, stimulation is then a contingency in case of poorer than expected reservoir quality. A worst-case well with a large skin value of 20 can perform with stimulation like a base-case unstimulated well. In other formations, stimulation will be integral to well design in order to optimise the project performance. For those cases the Coefficient of Performance can be improved from 7 to 25 with the aid of stimulation.

In Ultra-Deep Geothermal (UDG) recovery, the targets are reservoirs below $4000 \mathrm{~m}$, because industrial heat demand requires a minimum temperature of $120^{\circ} \mathrm{C}$ up to $250^{\circ} \mathrm{C}$. For an economic business case, the rate over a period of 15 to 25 years should be from 150 to $450 \mathrm{~m}^{3} \mathrm{~h}^{-1}$, depending on the boundary conditions.

Shallower reservoirs in the Netherlands often show very high permeability, but at great depth the target layers could have very low permeability (Veldkamp et al., 2018). Several stimulation methods can be used, of which hydraulic fracture stimulation with water (proppantless) is the primary candidate. Other stimulation methods are propped fracturing in sandstone, acid fracturing in carbonates and thermal stimulation.

For a geological play that is attractive for UDG in the Netherlands, the most likely stimulation method is with water fracturing, because propped fracturing would require a huge amount of proppant that is very costly. Based on analogues and conceptual designs, the expected flow rate is estimated under selected boundary conditions.

(c) The Author(s) 2020. This is an Open Access article, distributed under the terms of the Creative Commons Attribution licence (http:// creativecommons.org/licenses/by/4.0/), which permits unrestricted re-use, distribution, and reproduction in any medium, provided the original work is properly cited.

\section{Introduction}

\section{Description of hydraulic fracturing}

Hydraulic fracturing is a technique that has been used widely in the oil and gas industry since the 1950s. Currently, almost $90 \%$ of new gas wells drilled in North America are stimulated with hydraulic fracturing. In 2000 the number of treatment stages had grown to 50,000 a year, and with the development of very tight reservoirs the number of stages increased to 500,000 a year.

The basis of hydraulic fracturing is to inject fluid into a well above the minimum horizontal stress. This creates a crack (fracture) in the earth that is connected to the wellbore (Figure 1). Once the fracture is created, it is filled with high-permeability proppant, which holds the 


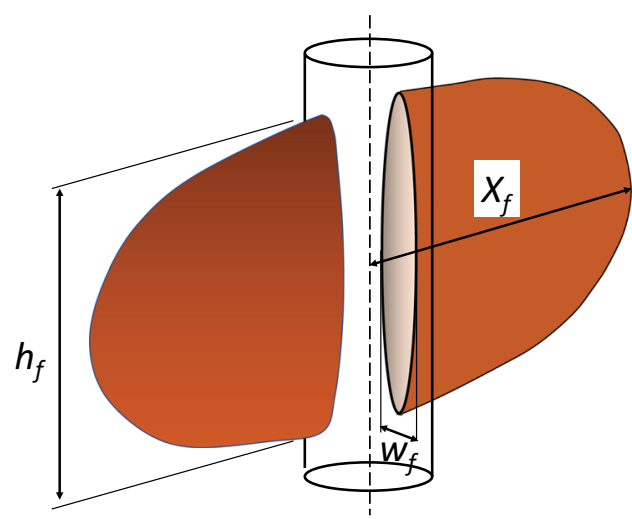

Figure 1. Idealised hydraulic fracture geometry for a vertical wellbore.

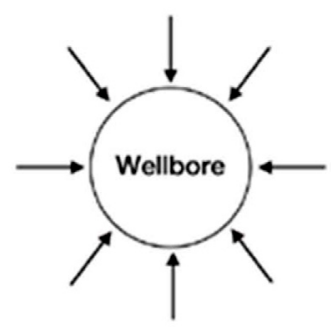

Radial flow

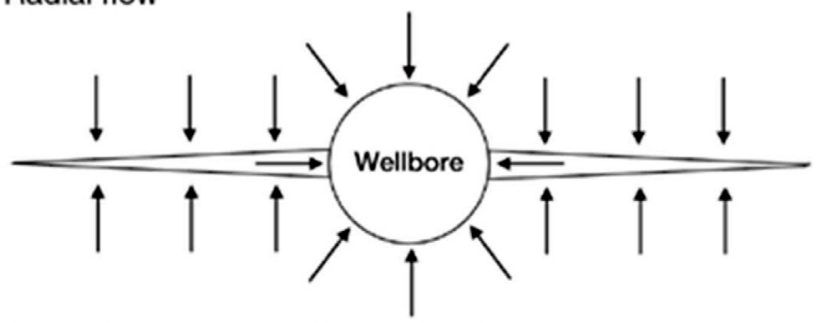

Hydraulically fractured vertical well

Figure 2. Inflow geometry for wellbore and hydraulic fracture.

fracture open once the pumping has stopped. The fracture area is very large compared to the inflow area of a normal well. The highpermeability proppant provides a path that allows the fluid to flow out of the reservoir and into the wellbore, or out of the wellbore and into the reservoir.

The enhanced productivity from a hydraulically fractured well is mainly due to the larger inflow area, compared to just the area of the wellbore. This is shown in Figure 2. The increase in area can easily be 3 orders of magnitude. The other main benefit of hydraulic fracturing is to mitigate vertical and horizontal reservoir heterogeneity by contacting the reservoir over a large area at a large distance from the well.

Hydraulic fracturing improves the productivity (or injectivity) of a well by increasing the connected area of the wellbore. This improvement can be used in different ways. For a given drawdown pressure, more fluid can be produced from the well. Or, for a fixed amount of fluid, the drawdown can be reduced. In the context of this application of geothermal heating, where a fixed amount of water is needed, the hydraulic fracture will reduce the drawdown needed to produce that amount of water. This has the effect of increasing the Coefficient of Performance (COP) of the project. $\mathrm{COP}$ is defined as produced geo-energy divided by injector and

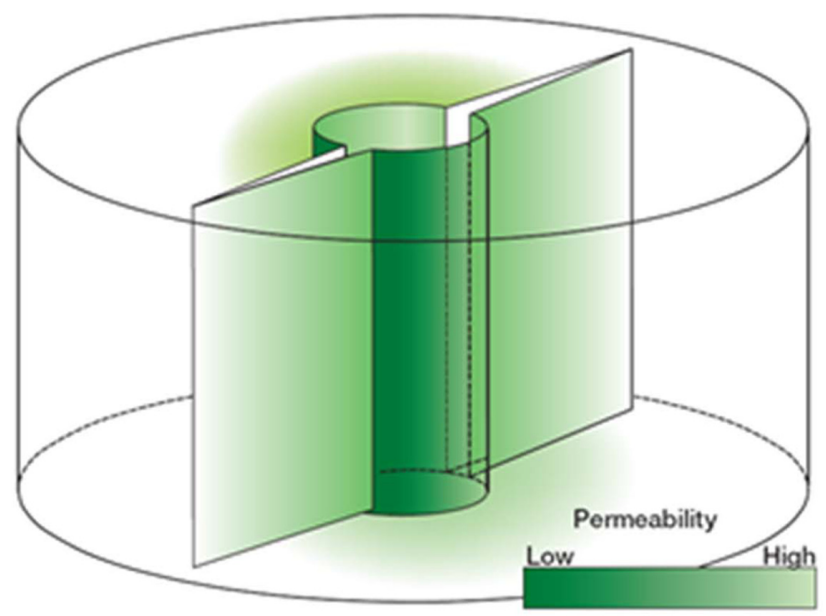

Figure 3. Skin bypass fracture in high-permeability formation.

producer pump energy. The factor of improvement in COP that can be achieved depends on the permeability of the formation and the initial skin. For high permeability, the COP may be doubled, while for lower permeability the COP can be increased by a factor of 5 or more. If there is a large skin (as explained in the next subsection), then the benefit can be even larger. Thus, even for a well that would be economic without fracturing, performing a hydraulic fracture stimulation to improve the COP can reduce the electricity demand for pumping. This benefit is equally applicable to the injector well if extra pressure is needed to inject the required fluid. The increase in well performance can also be used to reduce the number of wells needed to achieve a certain target for a multiwell development.

\section{Application of hydraulic fracturing for high-permeability reservoirs}

After drilling, the well usually is left with what is known as a 'positive skin'. This means that the actual inflow potential of the well is less than the theoretical (no skin) production. This skin is typically a region of damaged rock (with a lower permeability) around the wellbore. The damaged zone has usually been affected by the drilling fluid filtrate. Hydraulic fracturing in highpermeability reservoirs is typically used to bypass this skin and connect the wellbore to the undamaged reservoir (Figure 3). The presence of a sand-screen in a high-permeability well also acts like a positive skin, reducing the inflow potential of the well. Placing a hydraulic fracture outside the sand-screen can counteract the loss of production due to the sand-screen, which is needed to prevent the wellbore from filling up with formation sand. The fracture also acts as a filter, reducing the amount of formation fines that can collect and plug the screen. The lower drawdown due to the fracture also helps to minimise the production of formation fines. A special completion is used to place a fracture and pack the annulus outside the screen (Figure 4).

\section{Application of hydraulic fracturing for low-permeability reservoirs}

The application of hydraulic fracturing for low-permeability reservoirs is mainly for the purpose of production acceleration. This means that with the larger inflow area created by the hydraulic fracture, a much higher production or injection rate can be 


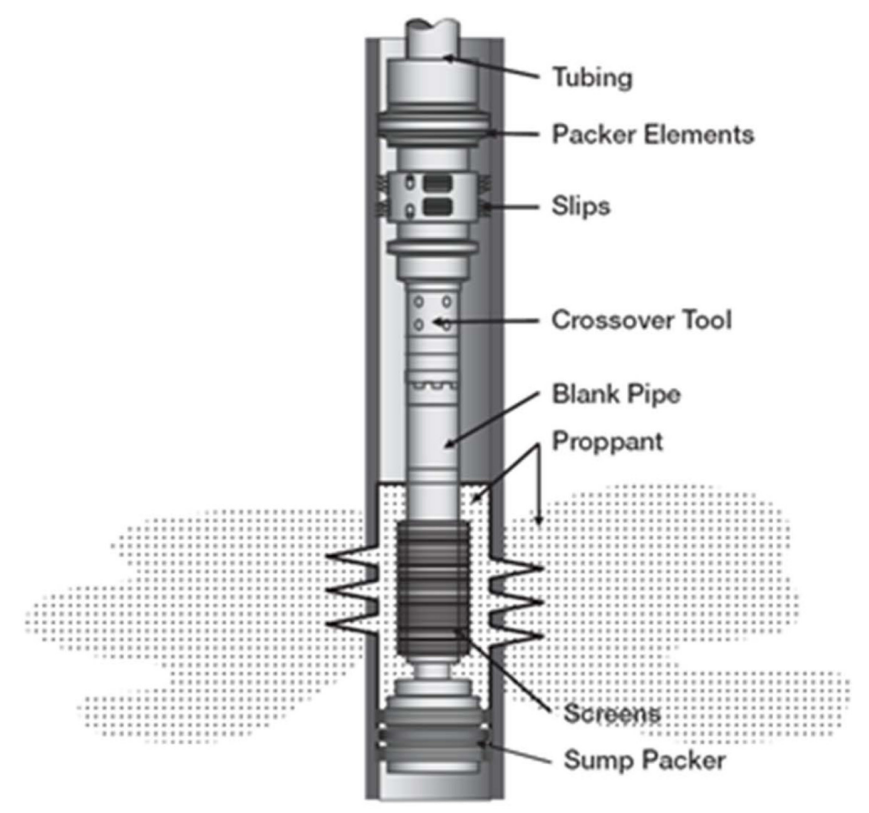

Figure 4. Frac pack completion string.

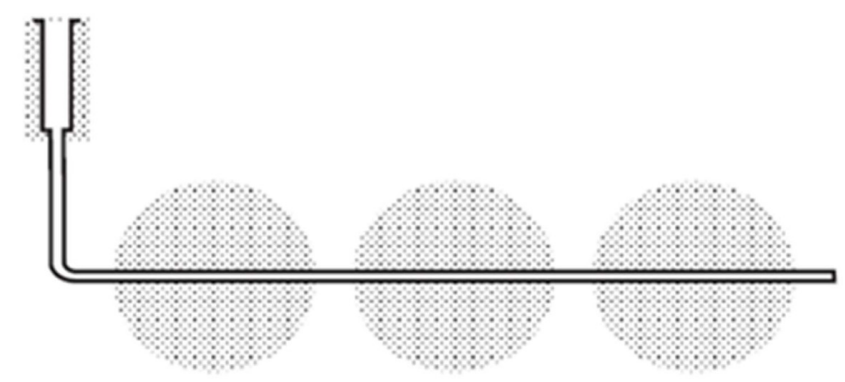

Figure 5. Horizontal well with multiple longitudinal fractures.

achieved during the initial 'transient' flow period. Once this 'transient' period is finished, the hydraulically fractured well acts like a 'normal' well with a very large effective radius of up to half the fracture half-length. As the permeability of the reservoir gets lower, it becomes more attractive to try to create a longer fracture length. In practice, since the fracture height also grows along with the length, there is a limit to how long a fracture can be created while still staying within the zone of interest, unless there happen to be strong barriers to fracture growth above and below the zone of interest. The 'transient' flow period is a function of the fracture length and the reservoir permeability. It can vary from months to years for very low-permeability reservoirs.

In cases where a hydraulic fracture in a vertical well still does not provide the required productivity, it is also possible to drill a horizontal well and place multiple hydraulic fractures along the length of the well. This effectively behaves as multiple vertical fractured wells for a fraction of the cost of drilling all the vertical wells. This approach is most attractive for very low-permeability formations where a very small well spacing would be needed to contact sufficient reservoir volume. For water injection, a horizontal well with longitudinal fractures is needed to create the right fluid front geometry (Figure 5).

The key benefit of horizontal multiple fractured wells in lowpermeability formations is that the productivity or injectivity scales linearly with the number of fractures, but the total well costs increase by a much smaller amount. For example, a horizontal well with five fractures might only cost the same as two vertical fractured wells, but would produce five times as much fluid initially.

\section{Stimulation of very tight reservoirs}

For producing high-temperature heat it is necessary to produce reservoirs at a depth of more than $4 \mathrm{~km}$. Several potential plays can be distinguished at a depth range between 4 and $6.5 \mathrm{~km}$, such as karst, fault or matrix porosity. The karst or fault plays could sustain very high rates but the high-permeability zones are localised so that the well needs to be connected to the karst or fault zone. The connection can be achieved by fracturing the well. Well stimulation is even more important in the matrix play since permeability at great depth is expected to be at best a few millidarcies.

If the karst play is available, it is probably the best option for deep geothermal heat production, but it is possible that only low-permeability reservoirs are available at great depth in the Netherlands. In that case the high-permeability heat exchanger for producing hot water has to be made by large-scale fracturing. Several conceptual fracture systems can be considered for achieving this goal. One way is to create a system of parallel propped fractures. This offers optimum control but it also requires gigantic amounts of proppant (at least some $4000 \mathrm{MT}$ ) to create an injection well with producers in a doublet or triplet configuration. Recent developments in pulsed fracturing may require less proppant, but that only halves the amount pumped. Another conceptual fracture system consists of a fracture network created by water injection (with perhaps some proppant near the wellbore) that can deliver a high surface area that yields an efficient heat exchanger. Such fracture systems have been created for recovery of hydrocarbons from very tight reservoirs, such as shale but it is obvious that this is only possible in rocks where water injection induces a fracture system (fracture network), rather than a single planar fracture.

\section{Methods and materials}

\section{Reservoir simulation methodology}

The predictions for the performance of the production and injection wells shown in this paper were made with a numerical reservoir simulation model. This model is limited to a single well, rather than a pair of wells, so some assumptions were made in order to capture the correct behaviour for this problem. Under steady-state conditions, the pressure at some point equidistant between the injector and producer well should be the same as the original reservoir pressure at this point. We can approximate this by modelling a very large drainage area (connected volume) for the well, so that the reservoir pressure during the simulation does not change significantly due to the finite volume of the simulation model. Even for the low-permeability case, steady-state conditions are reached quite rapidly (days). For the high-permeability case, steady-state conditions are reached immediately (hours).

For the injection well, we are injecting cool (higher-viscosity) water into a warm reservoir filled with lower-viscosity water. It is not possible to model this situation exactly using the single-well, single-layer model we chose for this study. If we model the reservoir around the injection well as being completely filled with cool water, this gives a much too pessimistic result, since it will take years before there is a significant cool flooded zone around the injector. We have therefore chosen to model the fluid in the injection well reservoir at its original temperature, which will better 
Table 1. Reservoir parameters for den Haag producer analogue well

\begin{tabular}{lrrr}
\hline Parameter & P05 & P50 & P95 \\
\hline$H(m)$ & 100 & 30 & 20 \\
\hline$K(m D)$ & 600 & 1330 & 1000 \\
\hline Kh (D-m) & 60 & 40 & 20 \\
\hline
\end{tabular}

Table 2. Reservoir parameters for den Haag injector analogue well

\begin{tabular}{lrrr}
\hline Parameter & P05 & P50 & P95 \\
\hline H $(m)$ & 100 & 30 & 20 \\
\hline K $(m D)$ & 750 & 2000 & 2250 \\
\hline Kh (D-m) & 75 & 60 & 45 \\
\hline
\end{tabular}

Table 3. Fluid properties for den Haag analogue

\begin{tabular}{lcc}
\hline Parameter & Producer well & Injector well \\
\hline Reservoir pressure (bar) & 219 & 179 \\
\hline Water viscosity $(\mathrm{cp})$ & 0.367 & 0.626 \\
\hline Water density $(\mathrm{sg})$ & 1.034 & 1.069 \\
\hline Temperature $\left({ }^{\circ} \mathrm{C}\right)$ & 73 & 40 \\
\hline
\end{tabular}

predict the initial years of injection. For the long-term injection behaviour, there are other effects (thermal and poroelastic) that need further study, which will also have an important effect for the long-term performance.

\section{Analysis and results}

\section{Fracturing performance for generic Delft sandstone reservoir}

Three reservoir quality scenarios were examined for a 'highpermeability' injector-producer pair, based on the expected properties for the Delft sandstone in the province of South-Holland. The reservoir properties for these scenarios are shown in Table 1 and Table 2, for the producer and injector wells respectively. A reservoir simulation model was created in order to predict the performance of the injector and producer wells without any fracture stimulation. The most important other parameters for these simulations are shown in Table 3.

As shown in the tables, three different scenarios were evaluated. Based on a statistical approach, these scenarios are defined as P05, P50 and P95. The P05 scenario is defined as the reservoir quality that will be exceeded in $5 \%$ of the cases and can also be considered the 'best-case' scenario. The P50 scenario is what can be expected at least $50 \%$ of the time, and can be considered the 'base-case' or 'most likely' scenario. The P95 scenario is the 'worst-case' scenario, as $95 \%$ of all wells should be at least as good as this case.

In order to simulate the hydraulic fracturing of these wells, we also need to estimate the most important rock mechanical properties: the Young's modulus and the minimum horizontal stress gradient. Since the modulus is usually correlated with the porosity and permeability, we used three different values of the modulus, to cover three different ranges of permeability. These values are
Table 4. Rock modulus estimates

\begin{tabular}{lc}
\hline Permeability (D) & Modulus (bar) \\
\hline Greater than 2 & 34,000 \\
\hline Between 1 and 2 & 69,000 \\
\hline Less than 1 & 138,000 \\
\hline Shale layer & 240,000 \\
\hline
\end{tabular}

shown in Table 4. Based on our regional experience, we estimated a minimum horizontal stress gradient of $0.147 \mathrm{bar} \mathrm{m}^{-1}$ for the sandstone layers and 0.1697 for the shale layers.

In order to make a realistic evaluation of the benefits of hydraulic fracturing, we first have to simulate the expected performance of the wells with a range of realistic skin values. The skin values used in this study were $0,+5$ and +20 . These correspond to 'best-case', 'base-case' and 'worst-case' situations. Simulations for all three skin values were performed for each of the $k h$ scenarios (P05, P50, P95).

A fracture treatment design was made and simulated for each $k h$ scenario for producer and injector (six in total). The result of the fracture treatment design simulation is an estimated fracture length and conductivity. An example of the estimated fracture dimensions for the P50 producer well case is shown in Figure 6.

In order to create this fracture, $235 \mathrm{~m}^{3}$ of cross-linked gel and $100,000 \mathrm{~kg}$ of ceramic proppant were used in the treatment design. The pumping schedule for this design is shown in Table 5. Similar simulations were performed for the other five cases. The cost of pumping such a stimulation treatment depends on the exact type of fluids and proppants used, and how many treatments are done in the same 'campaign'. We estimate a cost of $€ 250,000$ per well for the fracture stimulation, and an additional $€ 250,000$ of rig-time to perform the treatments. The resulting fracture dimensions are imported into a reservoir simulator, in order to simulate the expected productivity or injectivity of the wells after fracture stimulation.

The results of the fractured well can be compared with the three un-fractured cases with the different skin values $(0,+5$, +20 ); the flow rate and drawdown is listed for the different cases in Table 6. The comparison for the P50 case producer well is shown in Figure 7. The key observation from these results is that the worst-case drawdown required to obtain $150 \mathrm{~m}^{3} \mathrm{~h}^{-1}$, for the P95 case with a skin of +20 is 95 bar. With a fracture stimulation treatment, this can be reduced to only 13 bar. This is a $25 \%$ better performance than the un-fractured P50 best case, with a skin of zero, which requires a drawdown of 15 bar to achieve the same performance. This shows that hydraulic fracture stimulation in a good reservoir can effectively reduce the risk by enabling almost any well (P95) to perform as well as the P50 best-case expectation. Similar results are seen for the injection well. The energy expenditure was also computed, which can be compared with the produced energy to calculate the COP, defined previously. The input parameters are listed in Table 7 and the well injection pressure and drawdown are listed in Table 8. The computed COP is listed in Table 9. The improvement of well performance by stimulation results in increasing the COP from 7 to 39 , between the P95 cases without and with a frac, respectively.

\section{Deep geothermal stimulation of tight reservoirs (EGS)}

For a single planar fracture connecting the injector to a producer it will be impossible to achieve efficient heat recovery over a long 
Table 5. Treatment design for den Haag P50 producer well fracture stimulation

\begin{tabular}{|c|c|c|c|c|c|c|}
\hline Stage No. & Stage type & Fluid type & Clean volume $\left(\mathrm{m}^{3}\right)$ & Prop conc. $\left(\mathrm{g} \mathrm{L}^{-1}\right)$ & Stage prop. (kg) & Proppant type \\
\hline 1 & Main frac pad & Crosslinked $^{d}$ & 4.164 & 0 & 0.0 & \\
\hline 2 & Main frac slurry ${ }^{b}$ & Crosslinked & 11.356 & 120 & 1360.8 & $\operatorname{LWC}^{\mathrm{e}} 20 / 40$ \\
\hline 3 & Main frac slurry & Crosslinked & 11.356 & 240 & 2721.6 & LWC 20/40 \\
\hline 4 & Main frac slurry & Crosslinked & 15.142 & 360 & 5443.1 & LWC 20/40 \\
\hline 5 & Main frac slurry & Crosslinked & 15.142 & 480 & 7257.5 & LWC 20/40 \\
\hline 6 & Main frac slurry & Crosslinked & 15.142 & 600 & 9071.8 & LWC $20 / 40$ \\
\hline 7 & Main frac slurry & Crosslinked & 15.142 & 720 & 10886.2 & LWC 20/40 \\
\hline 8 & Main frac slurry & Crosslinked & 15.142 & 840 & 12700.6 & LWC 20/40 \\
\hline 9 & Main frac slurry & Crosslinked & 15.142 & 960 & 14515.0 & LWC 20/40 \\
\hline 10 & Main frac slurry & Crosslinked & 15.142 & 1080 & 16329.3 & LWC 20/40 \\
\hline 11 & Main frac slurry & Crosslinked & 15.142 & 1200 & 18143.7 & LWC $20 / 40$ \\
\hline 12 & Main frac flush ${ }^{c}$ & Linear $^{\mathrm{e}}$ & 87.064 & 0 & 0.0 & \\
\hline
\end{tabular}

${ }^{a}$ pad = fluid that initiates the fracture (without proppant).

bslurry = fluid that transports the proppant into the fracture.

cflush $=$ fluid that displaces last slurry from wellbore.

${ }^{d}$ crosslinked $=$ high-viscosity polymer fluid.

e LWC $=$ lightweight ceramic.

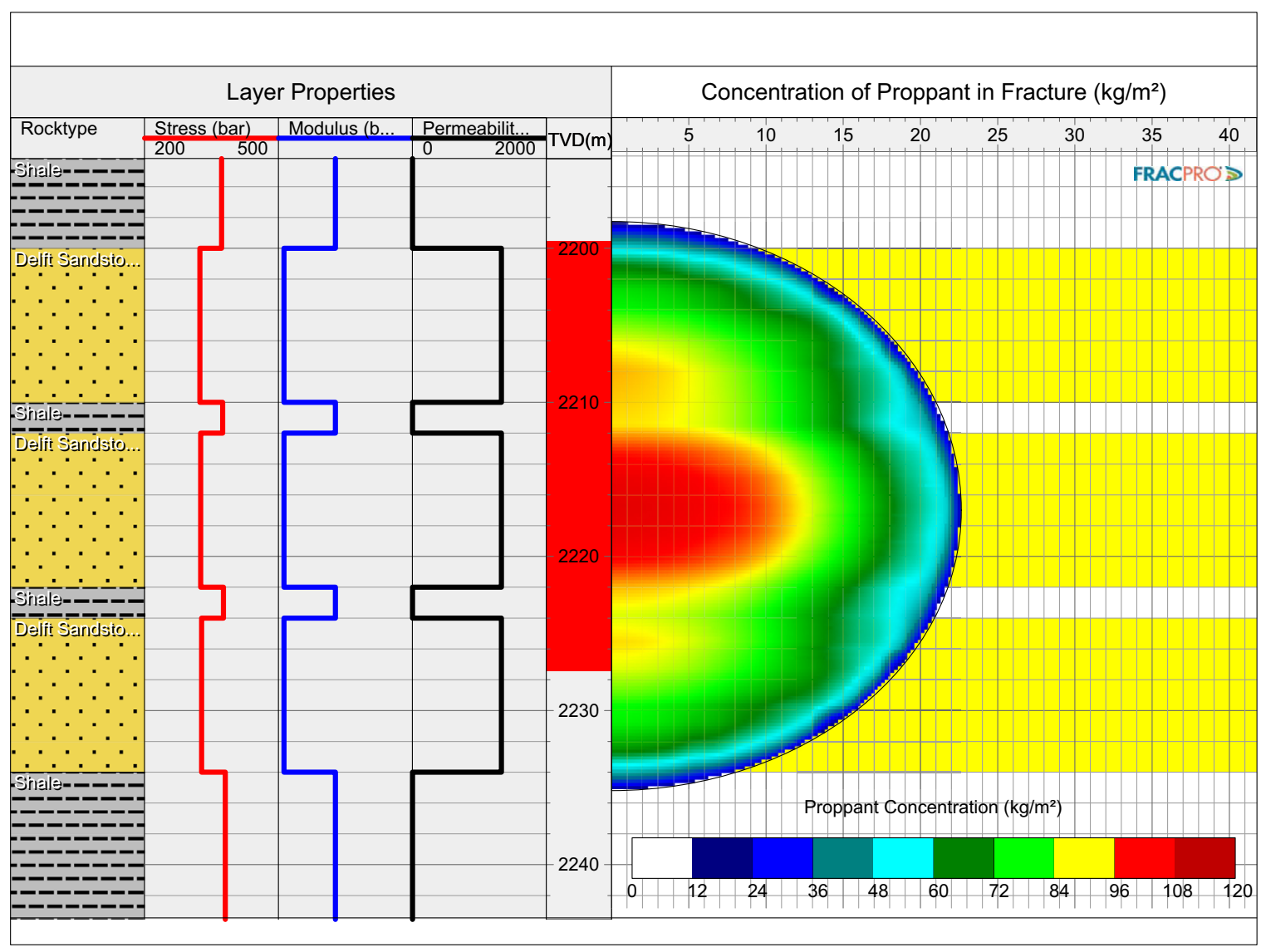

Figure 6. Simulated fracture dimensions and conductivity for P50 producer well.

period. The rate will be too low and also the cold water breakthrough will happen quickly since the fracture face surface will cool down so that heat will be recovered only in a small volume close to the fracture. A high rate and efficient recovery can only be achieved by combining many fractures. As Figure 8 shows, a large number of fractures could be pumped from a horizontal well. Provided the stress orientation is quite consistent along the lateral, all fractures will be parallel so that the injected water will flow along the 
Table 6. Flow rate and drawdown for the unstimulated cases with skin and the stimulated case

\begin{tabular}{lcccc}
\hline & Skin +20 & Skin +5 & Skin 0 & Frac \\
\cline { 2 - 5 } Rate $\left(\mathrm{m}^{3} \mathrm{~h}^{-1}\right)$ & \multicolumn{5}{c}{ Drawdown (bar) } \\
\hline 25 & 8 & 3.9 & 2.5 & 1 \\
\hline 50 & 16 & 7.8 & 5.1 & 2.1 \\
\hline 75 & 24 & 11.8 & 7.7 & 3.3 \\
\hline 150 & 48.1 & 23.5 & 15.3 & 6.6 \\
\hline 225 & 72.2 & 35.3 & 23 & 10.4 \\
\hline
\end{tabular}

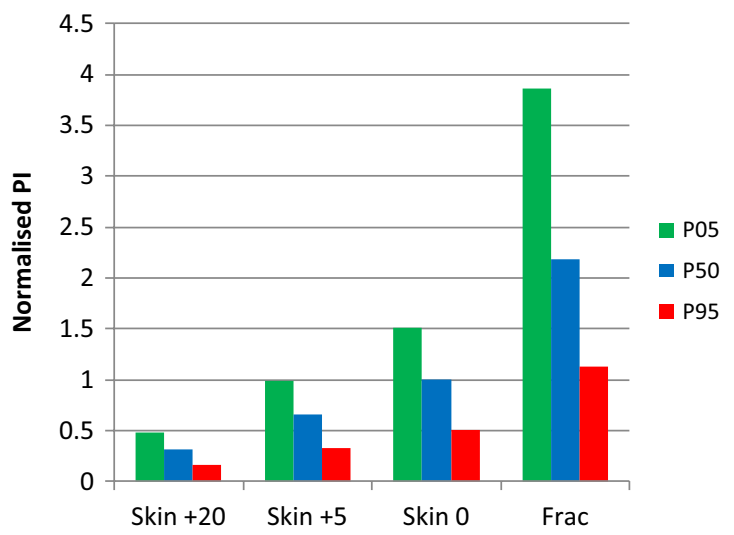

Figure 7. Productivity index (PI) of production well for matrix flow and a fractured well, normalised on the PI of a zero skin well in the P50 case.

fractures and can then be collected in two producers drilled through the tips of the fractures. Apart from the practical difficulty of achieving many aligned fractures of the same length, this concept requires a huge amount of proppant.

A model with both matrix flow through the formation and fracture flow can forecast the temperature at the producer. For 20 fractures with height of $100 \mathrm{~m}$ and half-length of $200 \mathrm{~m}$ the flow rate is $60 \mathrm{~m}^{3} \mathrm{~h}^{-1}$ and the temperature decline after 20 years is still small. For a flow rate of $180 \mathrm{~m}^{3} \mathrm{~h}^{-1}$ the fractures should be much bigger with larger height, which is deemed unrealistic.

A more practical approach would be to stimulate the injector with (proppantless) waterfracs that can then be connected to the producers. For an equivalent number of fractures of 100, the rate would be $180 \mathrm{~m}^{3} \mathrm{~h}^{-1}$ provided the injector-producer wells form a closed system.

Experience with EGS systems like Soultz or Habanero showed much lower maximum rates than $180 \mathrm{~m}^{3} \mathrm{~h}^{-1}$, so the flow rate should be seen as an upper limit. Moreover it is quite uncertain whether any of the potential target formations in the Netherlands will indeed have favourable properties to sustain fracture networks, so the achievable rate is a best case.

\section{Model of heat recovery with fractures}

If there are only tight formations available at great depth, the heat exchange has to happen in fracture systems that provide the required surface area. We consider two possible options: a system of large propped fractures between injector and producers (Figure 8) and a waterfrac network that is created between the injector and adjacent producers (Figure 9).
Table 7. Parameters used in the calculation of pump energy and COP (Robertson, 1988)

\begin{tabular}{lcc}
\hline Water density producer & 1034 & $\left(\mathrm{~kg} \mathrm{~m}^{-3}\right)$ \\
\hline Water density injector & 1069 & $\left(\mathrm{~kg} \mathrm{~m}^{-3}\right)$ \\
\hline Specific heat hot water & 3800 & $\left(\mathrm{~J} \mathrm{~kg}^{-1} \mathrm{~K}^{-1}\right)$ \\
\hline Temperature difference & 33 & $\left({ }^{\circ} \mathrm{C}\right)$ \\
\hline Pump efficiency & 0.73 & $(-)$ \\
\hline Hot water rate & 150 & $\left(\mathrm{~m}^{3} \mathrm{~h}^{-1}\right)$ \\
\hline Cum. hot water & 1.314 & $\left(\mathrm{million} \mathrm{m}^{3}\right)$ \\
\hline Geo energy produced & 47,327 & $(\mathrm{MWh})$ \\
\hline
\end{tabular}

Table 8. Well injection pressure (in $\mathrm{m}$ water) and drawdown for different cases and skin values. The fracture case is assumed to bypass any skin

\begin{tabular}{lccccc}
\hline \multirow{2}{*}{ Well } & & \multicolumn{4}{c}{ Skin } \\
\cline { 3 - 5 } Injector & Case & 20 & 5 & 0 & Frac \\
\hline \multirow{2}{*}{ Producer } & P05 & 239 & 116 & 75 & 46 \\
\hline & P50 & 299 & 147 & 95 & 82 \\
\hline & P95 & 399 & 196 & 128 & 112 \\
\hline & P50 & 309 & 151 & 98 & 37 \\
\hline
\end{tabular}

Table 9. Computed pump energy and resulting COP, computed with the simulation results in Table 8

\begin{tabular}{|c|c|c|c|c|c|c|c|}
\hline Fracture & & No & Yes & No & Yes & No & Yes \\
\hline \multirow[b]{2}{*}{ Case } & \multirow[b]{2}{*}{$S$} & \multicolumn{2}{|c|}{$\begin{array}{c}\text { Pump energy } \\
\text { producer }\end{array}$} & \multicolumn{2}{|c|}{$\begin{array}{c}\text { Pump energy } \\
\text { injector }\end{array}$} & \multirow{2}{*}{$\begin{array}{l}\text { COP } \\
(-)\end{array}$} & \multirow[b]{2}{*}{$(-)$} \\
\hline & & (MWh) & (MWh) & (MWh) & (MWh) & & \\
\hline P05 & 0 & 495 & 186 & 392 & 240 & 53 & 111 \\
\hline P50 & 0 & 750 & 324 & 500 & 432 & 38 & 63 \\
\hline P95 & 0 & 1486 & 628 & 672 & 589 & 22 & 39 \\
\hline P05 & 5 & 765 & 186 & 608 & 240 & 34 & 111 \\
\hline P50 & 5 & 1153 & 324 & 770 & 432 & 25 & 63 \\
\hline P95 & 5 & 2271 & 628 & 1030 & 589 & 14 & 39 \\
\hline P05 & 20 & 1570 & 186 & 1251 & 240 & 17 & 111 \\
\hline P50 & 20 & 2359 & 324 & 1570 & 432 & 12 & 63 \\
\hline P95 & 20 & 4694 & 628 & 2094 & 589 & 7 & 39 \\
\hline
\end{tabular}

Since most of the flow occurs in the horizontal plane, we use a $2 \mathrm{D}$ geometry. The boundary effect of the first and last fracture is neglected, so that we consider only a quarter of a reservoir block around a fracture.

The model computes the diffusion-convection heat transfer from the formation towards a fracture with cold water inlet (see Figure 10 which shows a plan view). It is assumed that near the tip of the fracture the heated water is collected by a production well. Heat transfer is computed with convection-diffusion equations in 


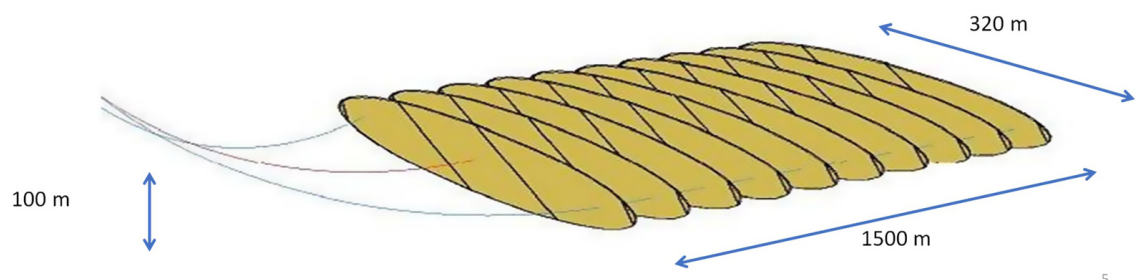

20 fracs; $63 \mathrm{~m}^{3} / \mathrm{h}$
Figure 8. Conceptual model of planar propped fracture system.

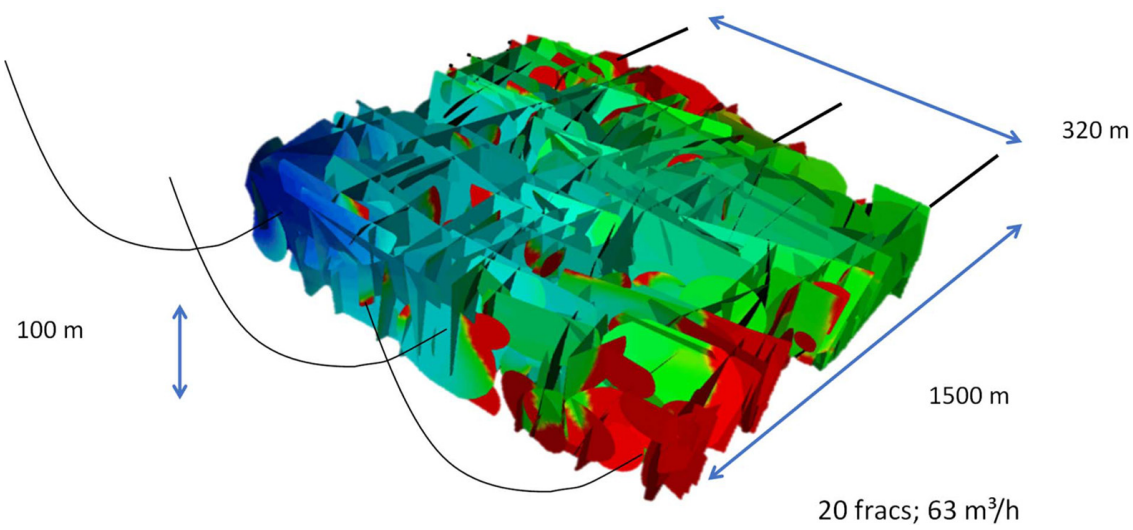

Figure 9. Conceptual model of fracture network.

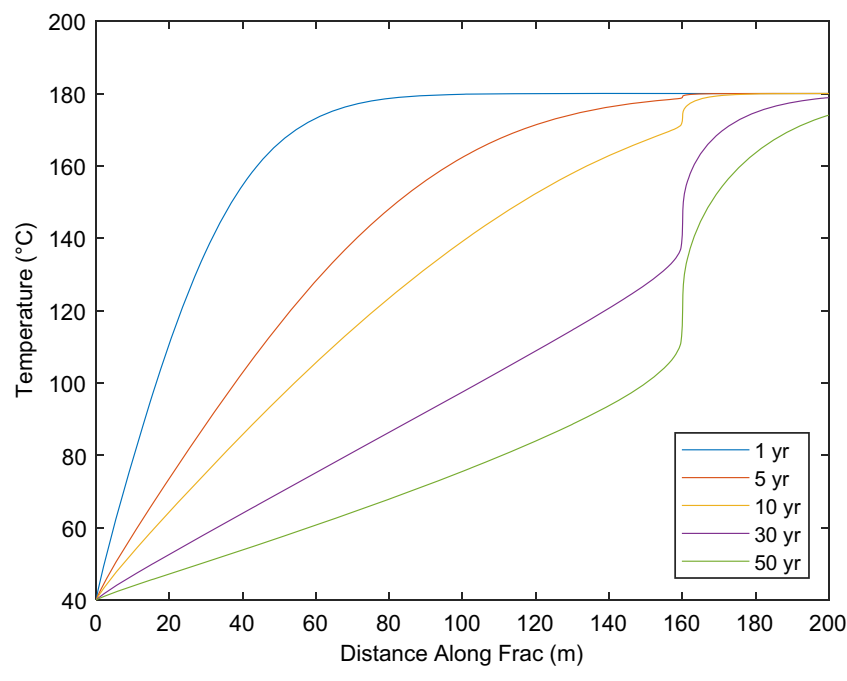

Figure 10. Simulation model that uses a quarter symmetry block around one fracture. The fluid pressure in the fracture causes fracture opening which induces conductivity of the fracture. Heat transfer in the fracture and surrounding rock is simulated with convection conduction including fluid infiltration from the fracture. The water is injected at $40^{\circ} \mathrm{C}$ with constant rate, and production is at the same rate. The production temperature is computed as a function of time.

both the rock and the fracture. The heat transfer coefficient is computed from the Reynolds number of the fracture flow and the Nusselt number using a correlation that was developed from laboratory tests (Zhang, 2015).

Flow in the formation is described with Darcy's law; this is also applied for the fracture flow. The conductivity of the fracture is given by a residual conductivity at reservoir pressure and augmented conductivity at higher pressure when the pressure exceeds the stress load on the fracture. The pressure profile is shown in Figure 11; the injection pressure exceeds the stress of $80 \mathrm{MPa}$ so that the conductivity is enhanced. The pressure at the production well falls below the reservoir pressure of $60 \mathrm{MPa}$, but the fracture conductivity is assumed to remain at the level of the residual conductivity so that sufficient production rate is achieved. Since this paper is only considering technical feasibility, we do not restrict the operation to what is currently allowed by legal requirements. Some regulators apply strict pressure limits, while others just require that the injection pressure does not propagate fractures. After stimulation, there is a considerable window between closure stress and propagation pressure, so that it would then be allowed to inject above closure pressure, which yields much better conductivity but does not propagate the fracture system.

The temperature along the fracture is computed for given injection rate of $150 \mathrm{~m}^{3} \mathrm{~h}^{-1}$ as a function of time. This generates a curve for the production temperature as a function of time (see Figure 12). The production temperature over time is plotted in Figure 13. After 20-30 years the production temperature falls to $155-140^{\circ} \mathrm{C}$, which may not be enough for the high-temperature heat applications envisaged. However, the geothermal well may later be switched to provide heat for other purposes such as district heating so that the well life can be extended.

\section{Discussion and conclusions}

In the Netherlands there is a positive experience with geothermal recovery from permeable reservoirs at moderate depth (1200$3000 \mathrm{~m}$ ). In some cases, poor reservoir quality poses a problem, and also fines production in unconsolidated sands can hamper efficient recovery. Both problems can be mitigated with propped fracturing of both producer and injector wells.

The pressure drop near the well is strongly reduced with even a moderately sized fracture. In high-permeability reservoirs the fracture length is of secondary importance, while fracture conductivity is dominant for optimising performance. Provided the treatment is designed to deliver high conductivity of the proppant pack, 


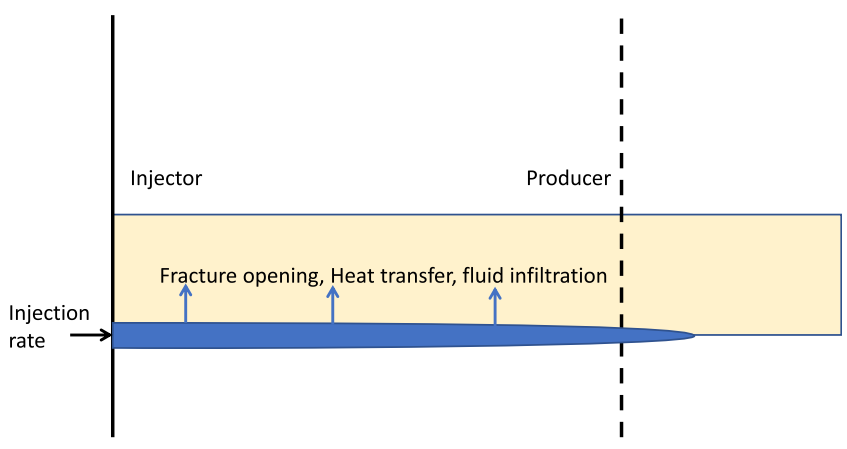

Figure 11. Temperature along the fracture for different injection times.

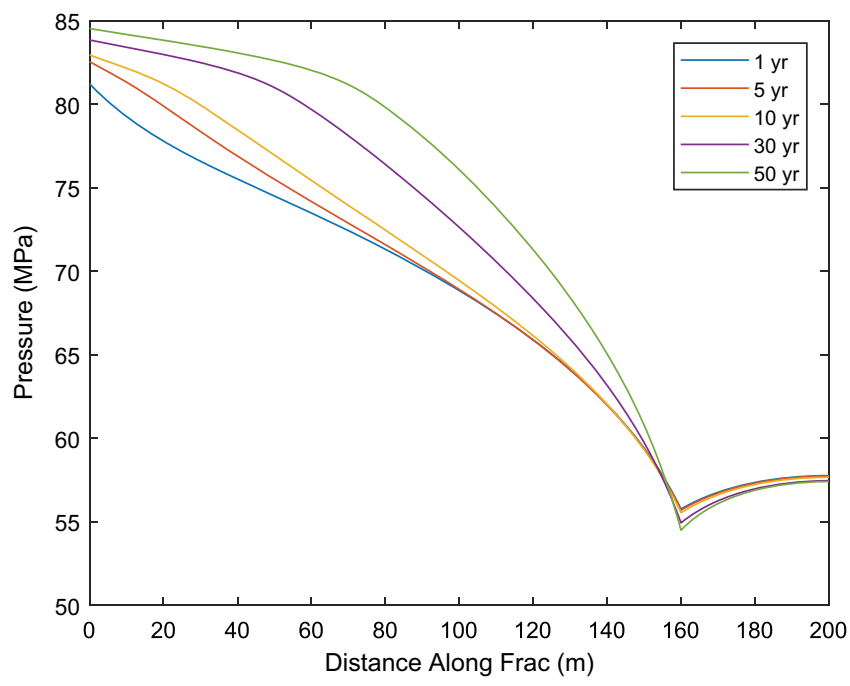

Figure 12. Pressure along the fracture, which changes somewhat over time due to changing fluid viscosity with temperature.

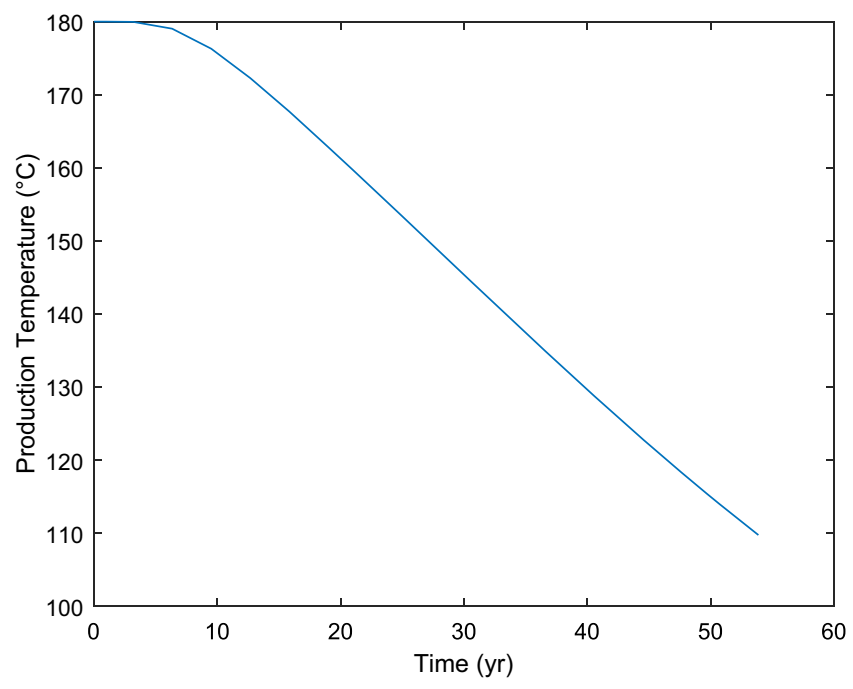

Figure 13. Production temperature vs time.

especially near the well, the productivity can be enhanced so that a P90 reservoir becomes comparable to a P50 reservoir quality in terms of well performance. In the realistic case of a well with a skin of 5 , the P95 case with a frac is even better than the P05 case with the same skin.
Fines can plug the near-wellbore reservoir, giving an even higher skin value. An advantage of a propped fracture is the huge enlargement of the inflow area. Therefore, the risk of plugging is much less compared with plugging of the sand face in an unfractured well, and with a lower drawdown there is less risk of fines production.

For each case it is important to investigate the economics of fracture stimulation of the wells, but it appears from the technical analysis that in most circumstances the business case for stimulation is strongly improved by stimulating the wells. The reason is that stimulation treatments cost less than $10 \%$ of the drilling cost.

High-temperature geothermal recovery is a completely different story since this requires drilling wells to deep formations which are commonly quite tight. Of course, if a high-permeability formation is found at great depth of about 5 to $6 \mathrm{~km}$, that will offer the best chance to produce water of $180^{\circ} \mathrm{C}$ at a high rate. For moderate permeability it may be feasible to stimulate wells to achieve a good rate, but a different concept is necessary in formations that lack permeability and even porosity. In those formations, the porous medium cannot act as an efficient heat exchanger so that the heat exchange must occur between numerous fractures and the formation. Fractures can provide the large surface area necessary for heat exchange in two ways: propped fractures or a network of water fractures and stimulated natural fractures.

It appears that creating many very long propped fractures will require a huge amount of proppant; with $200 \mathrm{MT}$ per treatment this would add up to $4000 \mathrm{MT}$ in total, which is very costly. A better option appears to be a fracture network system with artificial water fractures and stimulated natural fractures. The state of stress in the formation needs to be conducive to the formation of such a fracture network system, but in other applications (in other locations) this has been achieved. It is, however, uncertain whether this is possible, and at least it will require an extensive exploration and appraisal programme for even testing the proof of concept. Shallow geothermal recovery has been rather easy because it used proven techniques. The whole concept of EGS is in the development stage worldwide, so it cannot easily be applied in the Netherlands, which is expected to have adverse conditions for applying EGS technology, compared with other regions.

Commercial Ultra-Deep Geothermal projects exist in fractured or karst limestone reservoirs that need little stimulation, but all other plays are in the research and development phase, with massive water fracturing as the preferred stimulation method. Stimulation effectiveness varies strongly among these projects.

\section{Conclusions}

- For wells drilled in high-permeability formations, hydraulic fracturing can improve the performance of a base-case (P50, Skin +5$)$ well and make a worst-case $($ P95, Skin +20$)$ well perform as well as an un-stimulated base-case well. The COP for $150 \mathrm{~m}^{3} \mathrm{~h}^{-1}$ water production for the worst-case well can be increased from 7 to 39 by stimulating both injector and producer wells.

O Since fracture stimulation reduces the pumping pressures required, there is always a benefit in reducing the $\mathrm{CO}_{2}$ footprint of the project. 
- Wells drilled in low-permeability formations are not economic currently because of the poor reservoir transmissibility.

$\circ$ For the base-case (P50 Skin +5) the COP can be improved by fracture stimulation. With fracturing, it should be possible to achieve a rate of $150 \mathrm{~m}^{3} \mathrm{~h}^{-1}$ in most cases, which improves the well economics significantly.

- In low-permeability reservoirs at great depth, vertical wells with tight spacing or horizontal wells are necessary to achieve the required rate for a project.

$\circ$ Propped fractures can be used but require huge amounts of proppant which is costly.

$\circ$ Water fracturing is much cheaper but yields less control over fracture placement.

\section{References}

Murphy, H.D. \& Fehler, M.C., 1986. Hydraulic fracturing of jointed formations. SPE 1986 International Meeting on Petroleum Engineering, 17-20 March 1986, Beijing, China. SPE 14088. Conference proceedings.

Robertson, E.C., 1988, Thermal properties of rocks. Open-File Report 88-441. United States Geological Survey (Reston, VA).

Veldkamp, J.G., van Wees, J.D.A.M., Brunner, L.G., de Jong, A.P.A.M., Heijnen, L.J. \& van Langen, C. 2018. Play-based portfoliobenadering, eerste inzicht in zes voordelen voor veilig en verantwoord, kosteneffectief versnellen van geothermie. Report. TNO and EBN (Utrecht).

Zhang, G., Zhu, J., Li, J. \& Wang, Q. 2015. The analytical solution of the waterrock heat transfer coefficient and sensitivity analyses of parameters. World Geothermal Congress, 19-25 April 2015, Melbourne, Australia. Conference proceedings. 